\title{
Antiangiogenic drugs and advanced proliferative diabetic retinopathy
}

\author{
Drogas antiangiogênicas em retinopatia diabética proliferativa avançada
}

\author{
Jefferson Augusto Santana Ribeiro ${ }^{1}$, André Messias ${ }^{1}$, Rodrigo Jorge ${ }^{1}$
}

\begin{abstract}
Advanced diabetic retinopathy with tractional retinal detachment or persistent vitreous hemorrhage often requires surgical treatment with pars plana vitrectomy. Despite advances in vitrectomy, surgery for complications of diabetic retinopathy can be a challenge and may be impaired by intense fibrovascular proliferation. Antiangiogenic drugs have been used for the treatment of diabetic retinopathy because of their inhibitory action on vascular endothelial growth factor. In this review, we discuss aspects related to the adjuvant use of these drugs in vitrectomy for complications of diabetic retinopathy. Bevacizumab shows beneficial effects regarding the surgical technique facilitation, but its long-term benefit still needs to be studied.
\end{abstract}

Keywords: Anti-angiogenic drugs; Vitrectomy; Diabetic retinopathy; Retinal detachment; Vitreous hemorrhage

\begin{abstract}
RESUMO
As formas avançadas da retinopatia diabética com descolamento tracional de retina ou hemorragia vitrea persistente muitas vezes necessitam de tratamento cirúrgico com vitrectomia posterior. Apesar dos avanços em vitrectomia, a cirurgia em complicações da retinopatia diabética pode ser desafiadora e dificultada pela proliferação fibrovascular intensa. Os antiangiogênicos têm sido usados no tratamento da retinopatia diabética pela sua ação de inibição do fator de crescimento vascular endotelial. Nesta revisão, são discutidos os aspectos relacionados ao uso adjuvante de antiangiogênicos em vitrectomia para complicações da retinopatia diabética. O bevacizumabe mostra efeitos benéficos em facilitar a técnica cirúrgica, entretanto seu beneficio em longo prazo ainda precisa ser estudado.
\end{abstract}

Descritores: Inibidores da angiogênese; Vitrectomia; Retinopatia diabética; Descolamento retiniano; Hemorragia vítrea

\section{INTRODUCTION}

Advanced diabetic retinopathy with vitreous hemorrhage or tractional retinal detachment (TDR) is an important cause of severe visual loss in patients with proliferative diabetic retinopathy $(\mathrm{PDR})^{(1)}$, frequently representing an indication for pars plana vitrectomy in diabetic patients ${ }^{(2)}$. In these cases, surgery is not free from complications such as intraoperative vitreous hemorrhage and retinal rupture ${ }^{(3-4)}$. Also, during the postoperative period, these patients may suffer untoward events such as intraocular rebleeding and neovascular glaucoma(5).

Antiangiogenic drugs have been extensively used for the treatment of chorioretinal vascular disorders. The intravitreal use of bevacizumab, ranibizumab and pegaptanib has shown positive effects on diabetic retinopathy. The inhibition of vascular endothelial growth factor (VEGF) by these drugs can induce regression of diabetic neovascular retinopathy and combat exudative phenomena, thus being useful for the preoperative management of these patients $s^{(6-7)}$.

In the present article we review the use of antiangiogenic drugs as adjuvants in pars plana vitrectomy for the treatment of complications of diabetic retinopathy.

\section{VEGF AND DIABETIC RETINOPATHY}

Angiogenesis involves complex mechanisms with the participation of pro- and antiangiogenic molecules, being associated with both physiological processes and pathological conditions. VEGF is one of the angiogenic agents most extensively studied, playing an essential role in vascular development, angiogenesis and lymphogenesis ${ }^{(8)}$.
The family of endothelial growth factors includes placental growth factor (PIGF), VEGF-A, VEGF-B, VEGF-C, VEGF-D and the viral VEGF homologue VEGF-E ${ }^{(8)}$. Four VEGF-A isoforms have been identified in humans, with variation in the number of amino acids.

VEGF-A and -B participate more in angiogenesis, while VEGF-C and -D participate in lymphangiogenesis ${ }^{(9)}$. VEGF-A also acts by increasing vascular permeability. In addition to its action as a key factor in angiogenesis, VEGF also has a neurotrophic and neuroprotective activity on both the central and peripheral nervous systems ${ }^{(9)}$.

Three tyrosine kinase receptors, KDR (VEGFR-2), Flt-1 (VEGFR-1) and Flt-4 (VEGFR-3), mediate the action of VEGF, while two other receptors without tyrosine kinase activity, the neuropilins (NP), seem to be important VEGF co-receptors ${ }^{(8)}$.

In pathological processes, the production of VEGF and its receptors is related to tissue hypoxia, possibly sharing a common factor, hypoxia-induced factor (HIF), which accumulates in the presence of low oxygen levels and triggers the activation of a large number of genes, including the gene responsible for VEGF ${ }^{(8)}$. Hypoxia stimulates the expression of VEGF-A mRNA and reduces the expression of VEGF-C and VEGF-D mRNA ${ }^{(8)}$. The increase in VEGF results in a stimulus to vasodilation, an increase of vascular permeability, endothelial cell proliferation and activation of metalloproteinases that lyse the extracellular matrix, leaving space for the growth of a new vessel.

In diabetes, VEGF plays an important role in microvascular complications of the retina. The increase in VEGF-A acts as a vascular permeability factor in diabetic retinopathy and is accompanied by increased levels of VEGF receptors and, among them, the location
Funding: No specific financial support was available for this study.

Disclosure of potential conflicts of interest: J.A.S.Ribeiro, None; A.Messias, None; R.Jorge, None.

Correspondence address: Rodrigo Jorge. Faculdade de Medicina de Ribeirão Preto - Universidade de São Paulo. Av. Bandeirantes, 3.900, 12ªndar do Hospital das Clínicas, Campus USP Ribeirão Preto - SP - 14049-900 - Brazil - E-mail: rjorge@fmrp.usp.br 
of VEGFR-1 in the pericytes causes this factor to be responsible for the initial effects of increased VEGF-A levels. The increase of VEGFR2 is related to areas of vascular leakage, and its vascular expression has been suggested to occur only in areas with established diabetic retinopathy. VEGFR-3 has also been found to be increased in areas of vascular extravasation, indicating that other members of the VEGF family such as VEGF-C and -D may also participate in this process. Thus, the increased expression of VEGF-A observed during the preclinical period of diabetic retinopathy may act as mechanism of protection of the retinal vascular bed, whereas in advanced phases the alterations of retinopathy are associated with increased VEGF-A and VEGFR-2 in ischemic areas, leading to neovascularization and increased vascular permeability ${ }^{(8)}$. VEGF may also act by stimulating a narrowing of the capillary lumen due to hypertrophy of endothelial cells, thus contributing to capillary closure. In PDR, VEGF acts synergistically with other growth factors but is a necessary and sufficient factor for the induction of retinal and iris neovascularization in experimental models ${ }^{(8)}$.

\section{ANTI-VEGF DRUGS AND PROLIFERATIVE DIABETIC RETINOPATHY}

The effect of antiangiogenic drugs on PDR has been studied by several investigators. The ability of intravitreal pegaptanib to induce regression of retinal neovessels in PDR was first demonstrated. González et al. ${ }^{(10)}$, using injections of $0.3 \mathrm{mg}$ pegaptanib every 6 weeks for 30 weeks, showed that intravitreal pegaptanib was able to induce regression of retinal neovessels within three weeks in $90 \%$ of treated patients.

Intravitreal bevacizumab has a similar effect, inducing regression of retinal neovessels $s^{(6-7)}$. Spaide and Fisher ${ }^{(11)}$ detected regression of retinal neovascularization and of vitreal hemorrhage in two patients treated with $1.25 \mathrm{mg}$ bevacizumab one month after administration of the drug. Regression of neovessels of the anterior segment was also observed ${ }^{(12-13)}$. Oshima et al. ${ }^{(12)}$ reported that intravitreal bevacizumab induced regression of iris neovessels in 100\% of seven eyes with PDR within one week after administration of the drug, also facilitating the control of intraocular pressure.

Avery et al. $^{(6)}$, in a retrospective case series, observed rapid regression of retinal and iris neovessels in patients with PDR treated with intravitreal bevacizumab at doses of $6.2 \mu \mathrm{g}$ to $1.25 \mathrm{mg}$. Absence of leakage was observed by fluorescein angiogram in 100\% of eyes with PDR and persistent retinal neovessels 6 weeks after intravitreal administration of $1.5 \mathrm{mg}$ bevacizumab, although a significant reduction of leakage was already observed one week after the use of the antiangiogenic drug ${ }^{(7)}$. In a study by Tonello et al. ${ }^{(14)}$, the adjuvant use of $1.5 \mathrm{mg}$ intravitreal bevacizumab in panretinal photocoagulation for patients with high-risk PDR had a positive effect on the reduction of dye leakage observed by fluorescein angiography within a short period of time, with no significant changes in visual acuity compared to the group submitted to conventional treatment (laser photocoagulation). Mason et al. ${ }^{(15)}$ observed that an injection of $1.25 \mathrm{mg}$ bevacizumab before panretinal photocoagulation in eyes with PDR reduced foveal thickness and improved visual acuity within 24 weeks after laser therapy, thus being of help to avoid the complications associated with photocoagulation. In another study, Cho et al. ${ }^{(16)}$, when assessing the adjuvant use of $1.25 \mathrm{mg}$ bevacizumab in panretinal photocoagulation for PDR, observed a significantly lower occurrence of vitreous hemorrhage in the group receiving the antiangiogenic drug than in the group submitted only to laser. Although the bevacizumab dose commonly administered is usually $1.25 \mathrm{mg}$, lower doses can also induce regression of disc and retinal neovessels in PDR ${ }^{(17)}$.

\section{Preoperative administration of anti-VEGF drugs before pars PLANA VITRECTOMY FOR DIABETIC RETINOPATHY COMPLICATIONS}

Bevacizumab has been used preoperatively as an adjuvant in vitrectomy in patients with TRD, vitreal hemorrhage, mixed TRD, active fibrovascular proliferation (FVP) ${ }^{(3,18-30)}$, and neovascular glau- coma $^{(31)}$ (Table 1). Also, a pilot study of bevacizumab injected immediately after vitrectomy for vitreous hemorrhage was conducted ${ }^{(32)}$.

In these studies, the bevacizumab dose ranged from 1 to $2.5 \mathrm{mg}$ and the time of drug administration before surgery ranged from 1 to 30 days, with the patients usually being operated about 7 days after the intravitreal injection ${ }^{(18-20,22,26-29)}$. This time is considered to be safe in order to avoid complications of increased fibrosis and vitreoretinal traction, with regression of active neovessels and reduction of high VEGF levels characteristic of PDR having been observed ${ }^{(33)}$.

The preoperative use of bevacizumab proved to be favorable regarding technical aspects of the execution of pars plana vitrectomy, reducing surgical time and material exchange and facilitating the removal of fibrovascular membranes, in addition to reducing intraoperative hemorrhage and the need to use endodiathermy $(3,20,22-23,25,27,29-30)$. The improvement of the surgical technique for vitrectomy was probably due to the induction of neovascular regression and the reduction of vascular caliber ${ }^{(3,6-7,22,25,30)}$, with the consequent facilitation of the intraoperative manipulation of fibrovascular proliferations. However, other variables also influence the surgical technique in addition to the activity of neovessels in FVP, such as FVP extension and adhesion to the retina, factors that are little modified by the use of anti-VEGF drugs within a short period of time before surgery.

One of the main premises of the adjuvant use of an anti-VEGF drug in vitrectomy is to reduce the occurrence of postoperative hemorrhage, thus promoting a more rapid visual recovery. However, the postoperative results of these studies do not prove unequivocally the benefits of preoperative bevacizumab, with no randomized studies with long-term evaluation being available. While some studies have reported a statistically significant postoperative gain of visual acuity in patients previously treated with bevacizu$\mathrm{mab}^{(18-19,22-23,29)}$, others did not observe this benefit ${ }^{(20-21,24,28)}$. The occurrence of postoperative vitreous hemorrhage tends to be less frequent with the adjuvant use of bevacizumab ${ }^{(18-19,22-23)}$, although this result was not observed in other studies ${ }^{(21,24,28)}$. Postoperative vitreous hemorrhage can also be combated with gas buffering, which proved to be as effective as preoperative bevacizumab in a study by Yeung et al. ${ }^{(23)}$, although in that study the best results were obtained with the preoperative use of bevacizumab in combination with gas at the end of vitrectomy. Yang et al. ${ }^{(28)}$ suggested that, although the frequency of postoperative vitreous hemorrhage did not differ between groups treated or not with adjuvant bevacizumab in their study, the use of the antiangiogenic drug allowed a more rapid vitreous clearing during the postoperative period.

The reduction of vascular caliber after bevacizumab administration may result in lower intraoperative hemorrhage due to less damage to the vascular structures, with a consequent reduction of postoperative hemorrhage ${ }^{(22-23)}$. Although preoperative bevacizumab is eliminated from the vitreous with vitrectomy, its action may be prolonged by tissue penetration, since the presence of the drug in the choroid and inner retina one day after intravitreal administration has been demonstrated, continuing to be detectable 14 days after its use $\mathrm{e}^{(34)}$.

The intraoperative use of bevacizumab in vitrectomy has also been reported ${ }^{(32)}$. In the study by Romano et al.(32), a prospective case series in which $2.5 \mathrm{mg}$ bevacizumab was administered at the end of pars plana vitrectomy, the incidence of postoperative vitreous hemorrhage did not seem to be lower than the values reported in the literature. A possible explanation for this fact is that inhibition of VEGF during the immediate postoperative period may compromise vascular regeneration and favor re-bleeding ${ }^{(28)}$.

\section{Complications of the adjuVANT USE OF ANTI-VEGF DRUGS IN VITRECTOMY FOR DIABETIC RETINOPATHY}

The adjuvant use of antiangiogenic drugs in vitrectomy, however, may cause complications, as described in some case reports 
Table 1. Demographic and clinical characteristics of studies involving pars plana vitrectomy and adjuvant intravitreal bevacizumab for proliferative diabetic retinopathy

\begin{tabular}{|c|c|c|c|c|c|}
\hline Study & Diagnosis & Study design & $\begin{array}{c}\text { № of } \\
\text { patients }\end{array}$ & $\begin{array}{c}\text { Bevacizumab } \\
\text { (mg) }\end{array}$ & $\begin{array}{l}\text { Time between } \\
\text { IVB and PPV (days) }\end{array}$ \\
\hline Modarres et al. 2009 & PDR & Prospective, randomized, masked & 40 & 2.50 & $3-5$ \\
\hline Ahmadieh et al. 2009 & PDR - complications & Prospective, randomized, double-masked & 68 & 1.25 & 7 \\
\hline El-Batarny 2008 & $\mathrm{DR}(\mathrm{TRD}, \mathrm{VH})$ & Prospective, non-randomized & 30 & 1.25 & $5-7$ \\
\hline Lo et al. 2009 & PDR (TRD, VH, TRRD) & Retrospective, comparative & 137 & 1.25 & $1-27($ mean $=9.6)$ \\
\hline Romano et al. 2009a & PDR $(\mathrm{VH})$ & Prospective, pilot & 28 (30 eyes) & 2.50 & Intra-operative \\
\hline Yeh et al. 2009 & PDR (TRD, VH) & Prospective, case-control & 39 (41 eyes) & 1.25 & $7-9$ \\
\hline Yeung et al. 2009 & PDR (TRD) & Retrospective, case series & 64 (69 eyes) & 1.25 & $1-23($ mean= 9.6) \\
\hline Oshima et al. 2009 & PDR (TRD) & Retrospective, comparative & 59 (71 eyes) & 1.00 & $2-30($ mean $=7.6)$ \\
\hline Romano et al. 2009b & PDR $(\mathrm{VH})$ & Prospective, pilot & 31 (32 eyes) & 2.50 & $4-7$ \\
\hline Yeh et al. 2008 & PDR (TRD, VH) & Prospective, case series & 16 (18 eyes) & 1.25 & $6-14($ mean $=9)$ \\
\hline Yang et al. 2008 & PDR (active FVP) & Prospective, non-randomized & 39 (40 eyes) & 1.25 & $7-9$ \\
\hline Rizzo et al. 2008 & PDR (TRD, VH, TRRD) & Prospective, randomized & 22 & 1.25 & $5-7$ \\
\hline Ishikawa et al. 2009 & PDR & Prospective, case series & 6 (8 eyes) & 1.25 & $3-30$ \\
\hline Chen e Park 2006 & PDR (TRD) & Prospective, case report & 01 & 1.25 & 14 \\
\hline Lucena et al. 2009 & PDR (TRD) & Prospective, randomized, masked & 20 & 1.50 & 14 \\
\hline
\end{tabular}

$\mathrm{PDR}=$ proliferative diabetic retinopathy; $\mathrm{TRD}=$ traction retinal detachment; $\mathrm{VH}=$ vitreous hemorrhage; $\mathrm{TRRD}=$ combined traction and rhegmatogenous retinal detachment;

$\mathrm{IVB}=$ intravitreal bevacizumab; $\mathrm{PPV}=$ pars plana vitrectomy; $F \mathrm{P}=$ fibrovascular proliferation

and comparative studies in the literature. Lee and Koh ${ }^{(35)}$ reported an increase in the avascular foveal zone after posterior vitrectomy for diabetic vitreous hemorrhage with the intraoperative use of $2.5 \mathrm{mg}$ bevacizumab. Despite the concern about the increased retinal ischemia in diabetic retinopathy, it should be considered that the bevacizumab dose administered in this study was higher than that usually reported in the literature. No comparative studies evaluating the intraoperative use of an antiangiogenic drug in vitrectomy are available. A recent study on patients with diabetic macular edema and severe macular ischemia treated with intravitreal bevacizumab demonstrated improvement of visual acuity and of macular edema without worsening of retinal ischemia(36). The occurrence of a hole was observed by Gandhi et al. ${ }^{(37)}$ after the administration of $1.25 \mathrm{mg}$ bevacizumab before pars plana vitrectomy due to fibrovascular proliferation in diabetic retinopathy and was attributed to the tangential traction exerted by the fibrovascular tissue. Another complication related to the intraoperative use of bevacizumab was the occurrence of multiple retinal hemorrhages ${ }^{(38)}$. Postoperative subretinal hemorrhages were also observed by Yeh et al. ${ }^{(22)}$ in a prospective study of patients with PDR complications treated with $1.25 \mathrm{mg}$ bevacizumab 7 to 9 days before pars plana vitrectomy and were tentatively attributed to increased traction and to the formation of microruptures, although they did not have a significant effect on the surgical result.

The onset or progression of TRD and the occurrence of mixed retinal detachment are the most feared and most frequently reported complications. Considering only comparative studies, two of 10 articles reported TRD progression after the preoperative administration of the anti-VEGF drug ${ }^{(22,24)}$. Yeh et al. ${ }^{(22)}$ reported a case of TRD progression to mixed RD after the intravitreal injection of $1.25 \mathrm{mg}$ bevacizumab. In a retrospective study, Oshima et al. ${ }^{(24)}$ identified progression of retinal detachment in 7 eyes, i.e., 18\% of their patient sample treated with bevacizumab 2 to 30 days before vitrectomy (mean: 7.6 days). The dose of bevacizumab administered in this study was $1 \mathrm{mg}$, and the authors did not observe a relation of the time interval between injection of the antiangiogenic drug and vitrectomy with progression of the retinal detachment, with previous panretinal photocoagulation and ring retinal fibrosis surrounding the posterior pole being implicated as risk factors for progression. The management of PDR involves the treatment of retinal ischemia that leads to a pro-angiogenesis stimulus, which can be obtained by the use of antiangiogenic drugs such as bevaci- zumab, with a consequent reduction of the vasoproliferative stimulus in favor of fibrosis of existing fibrovascular structures and a consequent increase in retinal traction ${ }^{(39-40)}$. The administration of bevacizumab before vitrectomy to patients with intense fibrovascular proliferation and with a high ischemic stimulus may favor rapid fibrosis and cause a worsening of retinal detachment ${ }^{(22)}$. Thus, the contribution made by Oshima et al. ${ }^{(24)}$ should serve as an alert about which patients may benefit from a preoperative anti-VEGF drug and which patients should be followed-up at higher frequency after administration of the angiogenic drug.

\section{CONCLUSIONS}

Anti-VEGF drugs play a well-established role in PDR by inducing regression and caliber reduction of neovessels, an aspect exploited by the use of antiangiogenic adjuvants in vitrectomy for PDR complications.

The use of bevacizumab before vitrectomy for complications of diabetic retinopathy is associated with simplification of the surgical technique, with a reduction of the intraoperative complications commonly occurring among these patients. However, despite the observed tendency to less recurrent postoperative hemorrhage, there are no randomized prospective studies unequivocally demonstrating the long-term benefit of preoperative administration of anti-VEGF drugs. Other methods could also be used in order to improve recovery after surgery, such as cryotherapy in sclerotomy and gas buffering, and could be employed in combination with an antiangiogenic agent, resulting in the sum of benefits.

\section{REFERENCES}

1. Fong DS, Ferris FL $3^{\text {rd }}$, Davis MD, Chew EY. Causes of severe visual loss in the early treatment diabetic retinopathy study: ETDRS report no. 24. Early Treatment Diabetic Retinopathy Study Research Group. Am J Ophthalmol. 1999:127(2):137-41.

2. Aaberg TM, Abrams GW. Changing indications and techniques for vitrectomy in management of complications of diabetic retinopathy. Ophthalmology. 1987;94(7):775-9.

3. Ishikawa K, Honda S, Tsukahara Y, Negi A. Preferable use of intravitreal bevacizumab as a pretreatment of vitrectomy for severe proliferative diabetic retinopathy. Eye (Lond). 2009; 23(1):108-11.

4. de Bustros S, Glaser BM, Johnson MA. Thrombin infusion for the control of intraocular bleeding during vitreous surgery. Arch Ophthalmol. 1985;103(6):837-9.

5. Thompson JT, de Bustros S, Michels RG, Rice TA. Results and prognostic factors in vitrectomy for diabetic traction retinal detachment of the macula. Arch Ophthalmol. 1987;105(4): 497-502. 
6. Avery RL, Pearlman J, Pieramici DJ, Rabena MD, Castellarin AA, Nasir MA, et al. Intravitreal bevacizumab (Avastin) in the treatment of proliferative diabetic retinopathy. Ophthalmology. 2006;113(10):1695.e1-15

7. Jorge R, Costa RA, Calucci D, Cintra LP, Scott IU. Intravitreal bevacizumab (Avastin) for persistent new vessels in diabetic retinopathy (IBEPE study). Retina. 2006;26(9): 1006-13.

8. Witmer AN, Vrensen GF, Van Noorden CJ, Schlingemann RO. Vascular endothelial growth factors and angiogenesis in eye disease. Prog Retin Eye Res. 2003;22(1):1-29. Review.

9. Namiecinska M, Marciniak K, Nowak JZ. IVEGF as an angiogenic, neurotrophic, and neuroprotective factor]. Postepy Hig Med Dosw (Online). 2005;59:573-83. Review. Polish.

10. González VH, Giuliari GP, Banda RM, Guel DA. Intravitreal injection of pegaptanib sodium for proliferative diabetic retinopathy. Br J Ophthalmol. 2009;93(11):1474-8.

11. Spaide RF, Fisher YL. Intravitreal bevacizumab (Avastin) treatment of proliferative diabetic retinopathy complicated by vitreous hemorrhage. Retina. 2006;26(3):275-8.

12. Oshima Y, Sakaguchi H, Gomi F, Tano Y. Regression of iris neovascularization after intravitreal injection of bevacizumab in patients with proliferative diabetic retinopathy. Am Ophthalmol. 2006;142(1):155-8.

13. Silva Paula J, Jorge R, Alves Costa R, Rodrigues Mde L, Scott IU. Short-term results of intravitreal bevacizumab (Avastin) on anterior segment neovascularization in neovascular glaucoma. Acta Ophthalmol Scand. 2006;84(4):556-7.

14. Tonello M, Costa RA, Almeida FP, Barbosa JC, Scott IU, Jorge R. Panretinal photocoagulation versus PRP plus intravitreal bevacizumab for high-risk proliferative diabetic retinopathy (IBeHi study). Acta Ophthalmol. 2008;86(4):385-9.

15. Mason JO $3^{\text {rd }}$, Yunker JJ, Vail R, McGwin G Jr. Intravitreal bevacizumab (Avastin) prevention of panretinal photocoagulation-induced complications in patients with severe proliferative diabetic retinopathy. Retina. 2008;28(9):1319-24.

16. Cho WB, Oh SB, Moon JW, Kim HC. Panretinal photocoagulation combined with intravitreal bevacizumab in high-risk proliferative diabetic retinopathy. Retina. 2009:29(4):516-22.

17. Stergiou PK, Symeonidis C, Dimitrakos SA. Descending doses of intravitreal bevacizumab for the regression of diabetic neovascularization. Acta Ophthalmol. 2009 Oct 23. [Epub ahead of print]

18. Modarres M, Nazari H, Falavarjani KG, Naseripour M, Hashemi M, Parvaresh MM. Intravitreal injection of bevacizumab before vitrectomy for proliferative diabetic retinopathy. Eur J Ophthalmol. 2009:19(5):848-52.

19. Ahmadieh H, Shoeibi N, Entezari M, Monshizadeh R. Intravitreal bevacizumab for prevention of early postvitrectomy hemorrhage in diabetic patients: a randomized clinical trial. Ophthalmology. 2009;116(10):1943-8.

20. El-Batarny AM. Intravitreal bevacizumab as an adjunctive therapy before diabetic vitrectomy. Clin Ophthalmol. 2008:2(4):709-16.

21. Lo WR, Kim SJ, Aaberg TM Sr, Bergstrom C, Srivastava SK, Yan J, et al. Visual outcomes and incidence of recurrent vitreous hemorrhage after vitrectomy in diabetic eyes pretreated with bevacizumab (avastin). Retina. 2009:29(7):926-31.

22. Yeh PT, Yang CM, Lin YC, Chen MS, Yang CH. Bevacizumab pretreatment in vitrectomy with silicone oil for severe diabetic retinopathy. Retina. 2009;29(6):768-74.

23. Yeung L, Liu L, Wu WC, Kuo YH, Chao AN, Chen KJ, et al. Reducing the incidence of early postoperative vitreous haemorrhage by preoperative intravitreal bevacizumab in vitrectomy for diabetic tractional retinal detachment. Acta Ophthalmol. 2010;88(6): $635-40$

24. Oshima Y, Shima C, Wakabayashi T, Kusaka S, Shiraga F, Ohji M, Tano Y. Microincision vitrectomy surgery and intravitreal bevacizumab as a surgical adjunct to treat diabetic traction retinal detachment. Ophthalmology. 2009;116(5):927-38.

25. da R Lucena D, Ribeiro JA, Costa RA, Barbosa JC, Scott IU, de Figueiredo-Pontes LL, Jorge R. Intraoperative bleeding during vitrectomy for diabetic tractional retinal detachment with versus without preoperative intravitreal bevacizumab (IBeTra study). Br J Ophthalmol. 2009;93(5):688-91.

26. Romano MR, Gibran SK, Marticorena J, Wong D, Heimann H. Can a preoperative bevacizumab injection prevent recurrent postvitrectomy diabetic vitreous haemorrhage? Eye (Lond). 2009;23(8):1698-701. Comment in: Eye (Lond). 2010;24(2):388; author reply 389.

27. Yeoh J, Williams C, Allen P, Buttery R, Chiu D, Clark B, et al. Avastin as an adjunct to vitrectomy in the management of severe proliferative diabetic retinopathy: a prospective case series. Clin Experiment Ophthalmol. 2008;36(5):449-54.

28. Yang CM, Yeh PT, Yang $\mathrm{CH}$, Chen MS. Bevacizumab pretreatment and long-acting gas infusion on vitreous clear-up after diabetic vitrectomy. Am J Ophthalmol. 2008;146(2):211-7.

29. Rizzo S, Genovesi-Ebert F, Di Bartolo E, Vento A, Miniaci S, Williams G. Injection of intravitrea bevacizumab (Avastin) as a preoperative adjunct before vitrectomy surgery in the treatmen of severe proliferative diabetic retinopathy (PDR). Graefes Arch Clin Exp Ophthalmol. 2008;246(6):837-42

30. Chen $\mathrm{E}$, Park CH. Use of intravitreal bevacizumab as a preoperative adjunct for tractional retina detachment repair in severe proliferative diabetic retinopathy. Retina. 2006;26(6):699-700.

31. Miki A, Oshima Y, Otori Y, Kamei M, Tano Y. Efficacy of intravitreal bevacizumab as adjunctive treatment with pars plana vitrectomy, endolaser photocoagulation, and trabeculectomy for neovascular glaucoma. Br J Ophthalmol. 2008;92(10):1431-3.

32. Romano MR, Gibran SK, Marticorena J, Wong D, Heimann H. Can an intraoperative bevacizumab injection prevent recurrent postvitrectomy diabetic vitreous hemorrhage? Eur J Ophthalmol. 2009;19(4):618-21

33. Sawada O, Kawamura H, Kakinoki M, Sawada T, Ohji M. Vascular endothelial growth factor in aqueous humor before and after intravitreal injection of bevacizumab in eyes with diabetic retinopathy. Arch Ophthalmol. 2007;125(10):1363-6

34. Heiduschka P, Fietz H, Hofmeister S, Schultheiss S, Mack AF, Peters S, Ziemssen F, Niggemann B, Julien S, Bartz-Schmidt KU, Schraermeyer U; Tübingen Bevacizumab Study Group. Penetration of bevacizumab through the retina after intravitreal injection in the monkey. Invest Ophthalmol Vis Sci. 2007:48(6):2814-23.

35. Lee SJ, Koh HJ. Enlargement of the foveal avascular zone in diabetic retinopathy after adjunctive intravitreal bevacizumab (avastin) with pars plana vitrectomy. J Ocul Pharmacol Ther. 2009:25(2):173-4.

36. Bonini-Filho M, Costa RA, Calucci D, Jorge R, Melo LA Jr, Scott IU. Intravitreal bevacizumab for diabetic macular edema associated with severe capillary loss: one-year results of a pilot study. Am J Ophthalmol. 2009;147(6):1022-30, 1030.e1-5.

37. Gandhi JS, Tan LT, Pearce I, Charles SJ. Bevacizumab (Avastin) as a surgical adjunct in diabetic vitrectomy for fibrovascular disease. Eye (Lond). 2009;23(3):742-3.

38. Lee CS, Koh HJ. Multiple retinal haemorrhages in diabetic retinopathy after adjunctive intravitreal bevacizumab (Avastin) with pars plana vitrectomy. Acta Ophthalmol. 2008, 86(7):812-3.

39. Mosesson MW. Fibrinogen and ûbrin structure and functions. J Thromb Haemost. 2005 3(8):1894-904

40. Kuiper EJ, Van Nieuwenhoven FA, de Smet MD, van Meurs JC, Tanck MW, Oliver N, et al. The angio-fibrotic switch of VEGF and CTGF in proliferative diabetic retinopathy. PLoS One. 2008;3(7):e2675

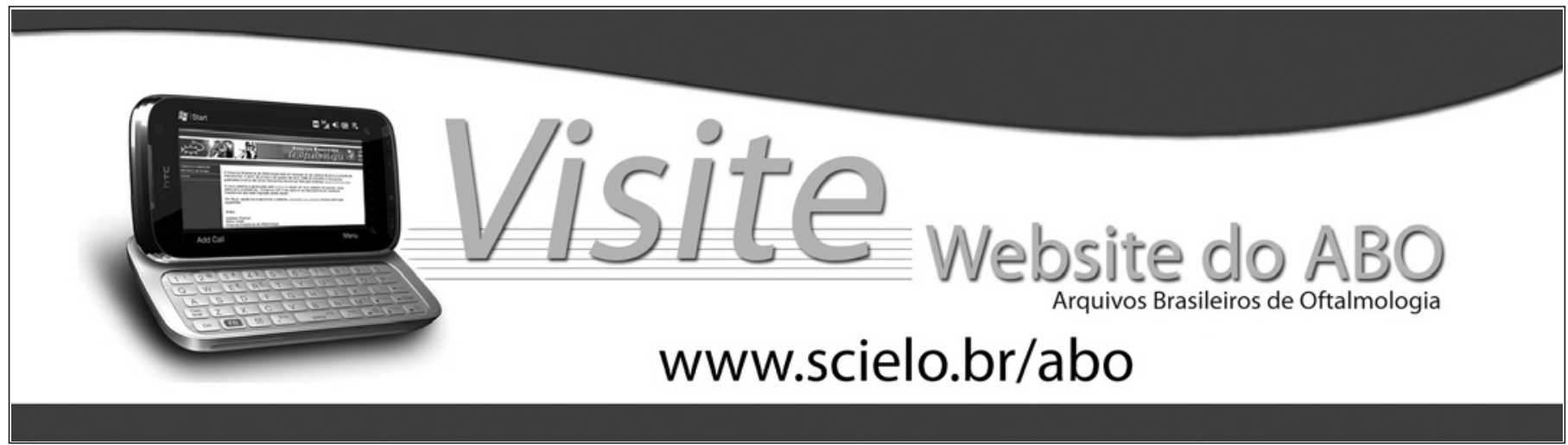

